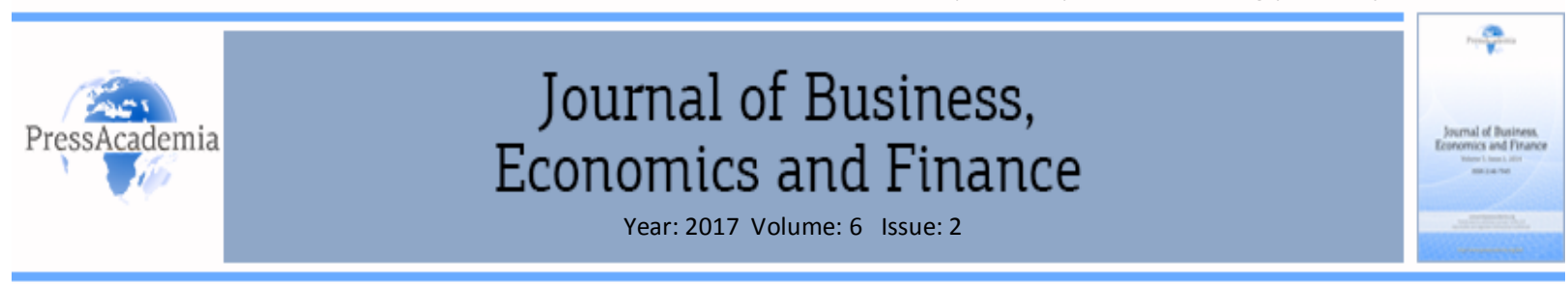

\title{
ROLE OF KNOWLEDGE MANAGEMENT IN ACHIEVING ORGANIZATIONAL PERFORMANCE: PROPOSED FRAMEWORK THROUGH LITERATURE SURVEY
}

\author{
DOI: 10.17261/Pressacademia.2017.501 \\ JBEF- V.6-ISS.2-2017(7)-p.125-133
}

\author{
Muhammad Yousaf Jamil \\ University of Management and Technology, Director Quality Enhancement Cell, Lahore, Pakistan. yousaf.jamil@umt.edu.pk
}

\section{To cite this document}

Jamil, M. Y. (2017). Role of knowledge management in achieving organizational performance: proposed framework through literature survey. Journal of Business, Economics and Finance (JBEF), V.6, Iss.2, p.125-133.

Permemant link to this document: http://doi.org/10.17261/Pressacademia.2017.501

Copyright: Published by PressAcademia and limited licenced re-use rights only.

\begin{abstract}
Purpose- Keeping in view the increasing demand of knowledge management, Researchers has recognized the need for structures for appraising the influence of knowledge management (KM) on organizational performance (OP). Despite of the wide performances of KM, at present there is no uniform structure for evaluating the OP. The basic intent of this study / research is to plan the appropriate methodologies to evaluate the impact of KM to enhance OP.

Methodology- At the end of this paper, the author proposes a theoretical model based on comprehensive and inclusive researches in the extent of KM and OP.

Findings- Through a wide-ranging organization of KM practices, the probable model discovers the influence of each KM practice on enlightening the level of OP.

Conclusion- The suggested model can play an important part in the management of the processes of KM execution in order to explore as it affects on OP.
\end{abstract}

Keywords: Knowledge management (KM), organizational performance (OP), leadership, organizational culture. JEL Codes: L25, O32, M11

\section{INTRODUCTION}

Knowledge has turned into a vital factor of creation notwithstanding the conventional factors land, work and capital which is the main factor of maintainable aggressiveness for associations (Jasimuddin, 2008; Sher and Lee, 2004; Drucker, 1992). The old establishment of industrialized economies has now moved from natural resources to intellectual resources (Lee and Choi, 2003). The thinkers and Management Researchers have announced a time of KM in which associations are progressively consider the knowledge as a profitable and vital asset (Zaied et al., 2012; Choi et al., 2006; Bollinger and Smith, 2001; Zack, 1999; Teece, 2000). Nonaka et al., (2014) emphasize on the supportable creativity in associations to accomplish maintainable assertiveness in the Organizational environment through consistent production of new knowledge (Nonaka et al., 2014; Krogh et al., 2012; Nonaka and Takeuchi, 1995; Nonaka, 1994; 1991). Schulz and Jobe (2001) additionally stated that KM center systems are more powerful than others. Dish and Yang, (2010) and Choi et al., (2008) have considered the positive relationship between KM techniques and Organizational Performance (OP) prompting to organizational performance in Korean and Chinese viewpoints separately. Jasimuddin (2008) and Zack (1999) have additionally set the comparable connections between KM techniques and OP. In accordance with the past studies the 
essential target of this study is to portray the immediate impact of KM center system (characterized by Choi et al., 2008) on organizational performance. In accordance with framework approach this study plans to investigate the immediate relationship between KM systems and organizational. Notwithstanding this the knowledge base of an organization is for the most part seen as the principal factor and this has been affirmed by the scientists like Tubigi, M. An., and Alshawi, S. N. (2012). Organizational Performance (OP) includes three particular ranges of firm results: (1) Financial performance; (2) Market performance; and (3) Shareholder return (total shareholder return, financial esteem included, and so on.). As per the predominant examines, it has likewise been caught as one of the variable because of which $\mathrm{km}$ additionally influences. The organizations have now begun actualizing venture asset arranging (ERP). The author of this paper concentrated on (ERP) because of the enhanced enthusiasm on the connection among ERP and OP. The possibility of "organizational culture "has in like manner been seen as a basic variable having influence on KM and OP. This thought is generally conveyed as "knowledge sharing culture" King, w. R. (2007). In an investigation finished by Ernest and young foundation on four hundred and thirty one European and American firms, Cross, R., and Baird, I. (2000) specified that oc is the transcendent square in knowledge trade. In study coordinated by (Mccann and Buckner,2004), social obstacles one of the middle factors which ruins the execution of KM qualities. Instructing of a gainful and effective culture underscores on knowledge sharing, trust in interfaces and creative ability (Lawson, 2003). On the basis of the detailed and comprehensive literature survey on the topic, the author proposes a framework describing the impact of Knowledge Management (KM) practices on Organizational Performance (OP).

\section{GAP ANALYSIS}

Since, the noteworthiness of knowledge in business associations has turned into a point of convergence for analysts, academicians and experts now days (Wu and Lin, 2009) and particularly in the most recent decade, knowledge creation hypothesis has pulled in consideration towards this vital resource (Nonaka et al., 2006). The organizations having abilities to investigate new knowledge reliably or having versatile fitness, they have dynamic upper hand (Mitchell and Boyle, 2010). Since, knowledge in business associations is a wellspring of upper hand in this way understanding and dealing with the elements of knowledge is exceptionally basic aspect (Heinrich and Lim, 2005). The positive relationship between knowledge management strategies and organizational performance and performance has been posited by several researchers in the literature. For instance, Yang (2010) and Choi et al., (2008) empirically established a positive association between knowledge management strategies and organizational performance in Korean and Chinese business organizations respectively. Bratianu and Orzea (2010), accentuating the Nonaka and Takeuchi's (1995) model, argued that the knowledge creation does not have an absolute result but it is based on organizational context. Gupta et al., (2006) on the other hand emphasized on an effective interplay between exploration and exploitation of organizational knowledge for sustainable competitive advantage. Since it has been established theoretically in the literature that knowledge can be acquired from outside and can be managed through effective and sophisticated IT systems but it can never be testified empirically. Therefore, why not this argument is investigated by hypothesizing the direct relationship between KM strategies and organizational performance? The importance of this research is to contribute towards body of knowledge in relation to the impact of KM on Effectiveness through literature survey on Concepts of KM, its several dimensions, Elements of OP, Prominent OP Improvement Models and relationship of KM processes and OP. This paper proposes a framework after having gone through the literature on the subject and the author assumes that if implemented in the Organizations can enhance the Organizational performance excellence.

1. To propose a model of KM Organization and its components.

2. Impact of KM on OP.

The importance of this research is to contribute towards body of knowledge in relation to the impact of KM on Effectiveness through literature survey on the following topics:

- $\quad$ Concepts of KM.

- Several Dimensions of KM.

- $\quad$ Elements of OP.

- Prominent OP Improvement Models

- Relationship of KM processes and OP.

\section{LITERATURE REVIEW}

The fundamental concern for researchers in the field of $\mathrm{KM}$ is endeavoring to scrutinize the means in which the performance of the organization is affected. Marqués and Simón (2006) conducted an experiential research on 222 Spanish firms in which the authors found out the link amongst KM and OP. Likewise, the research conducted by McKeen, Zack and Singh (2009) shows a significant impact of KM on Organizational Performance (OP). The study revealed that KM has positive relationship with OP. 
Knowledge is considered the most important resource for organizations working in dynamically -competitive environments Eisenhardt, K. M., and Martin, J. A. (2000). . In a high-rivalry environment, an association's capacity to acclimatize individuals' knowledge and develop new knowledge decides its focused power (Smith, Collins, and Clark, 2005). That knowledge creation exercises manufacture aggressive power has been very much shown by researchers who have examined an extensive variety of associations Tompson, H. B., and Tompson, G. H. J. (2013).

Knowledge Management: Considering the plan made by experts, 1980 decade was named Quality Development decade, 1990 was named Re-designing decade and at last, 2000 is known as KM decade. KM has been climbed as determinant of change Darroch, J. (2005). The knowledge, learning and development are interrelated builds. At the end of the day, learning happens when knowledge is utilized as a part of the association and at last this learning comes about into creativeness and improvement (Darroch and McNaughton, 2003). Two people's knowledge which get the same data is not indistinguishable. (Because of the expanding significance of knowledge in the time of knowledge economy, associations definitely must be mindful about ideas like creativity, development entrepreneurship, increasing practical, upper hand. KM is a course of action of methods for cognizance and relating knowledge enter resources in an organization. It is an organized methodology which recommends modus operandi for acknowledgment, appraisal, arranging putting away and applying knowledge with a specific end goal to address the issues and points of the organization. Seidler-de Alwis, R., and Hartmann, E. (2008). KM is a practice by which associations can recognize, select, arrange, circulate and transmit essential data and encounters which would be utilized as a part of exercises like issue determination, dynamic learning, urgent programming and principal organization. (Gupta, 2000). However it can be affirmed that today KM aptitudes could be used for entering creativeness as a piece of relationships. In present day economy, knowledge is the wellspring of reasonable, cutting edge enhancements and other standard factors like land, workforce and money are staying at ensuing levels of criticalness (Druker,1993).

Knowledge Management Cycle: The methods of KM cycle are as follows:

1) Knowledge creation: Organizations have cognizant exertion from both inside and outside to look at and depict fitting learning resources. It is conceivable to make new knowledge by finding new ways which work force have found for doing assignments, or find new learning from outside sources. (Elliot Temple, 2010)

2) Knowledge capture: New knowledge is known as basic and fitting course to satisfy contemporary and future needs. Keeping knowledge is a sensible way which sort out the way towards getting, expelling and appropriating knowledge. (Cook, S.D.N. and Brown, J. S. Crossing over, 1999)

3) Knowledge organization: New knowledge is made and refined by segregating it keeping in mind the end goal to give a broad once-over of pleasing parts of knowledge in relationship with various things and organizations. Knowledge is organized inside an affiliation and lines, properly it could be searched for, researched and spared. (Nonaka, I., Umemoto, K., and Senoo, D, 1996)

4) Knowledge storage: Modern knowledge is spared in a way that individuals is an organization have enlistment to it. Information base organization and information sparing improvement can help to the procedure. (Nonaka, I., 1994)

5) Knowledge dissemination: Based on the particular needs of the clients, in an effective sensible manner knowledge ought to be appropriated. Moreover it is presented to pertinent instruments to make it sensible for all clients. (Anderson, J. R., 1983)

6) Knowledge Application: Knowledge is utilized as a part of a setting in which clients can learn other than make new information. In learning process there must be examination and major evaluation of contemplations courses of action and information. (Polanyi M., 1962)

Organizational Performance (OP) can be judged by an extensive variety of forms constituency, realizing an extensive variety of explanations of "productive performance". Each of these perspectives of OP can be engaged to be novel. Further, every organization has a unique course of action of conditions, making performance estimation basically situational (Cameron and Whetton, 1983). Both of these issues are unjustifiable for researchers, since theory building incorporates putting forth and testing expressions that brighten or predict a particular marvel (all around addressed as an estimation of a destitute variable in a model) that remaining parts steady over a wide extent of specific events (Van de Ven, 1989: Weick, 1989). While it is possible to develop a multi characteristic model of OP, amassing a model that locations different forms community gets the opportunity to be dangerous, since each social affair may have restricting targets. As needs be, a bound together perspective of general OP is critical to execute this investigation. As necessities be, this proposal takes a gander at organizational performance from a lone body electorate perspective, that of the standard stockholder of income driven affiliations. Starting here of view, powerful OP can be compared to productive regard creation for essential stockholders. In coming segments, I fight that this perspective commonly contrasts regard creation and organizational cash related performance; as requirements be, this paper addresses the estimation of organizational financial performance. 
Weick, 1989). Since learning is instantly getting to be noteworthy divide of the OP (Choi and Lee, 2002), it is as needs be energetic that KPIs and estimation strategies are set up so as to allow Practitioners to appreciate the improvement of organizational information. (Decarolis and Deeds; Davenport, 1999) found one of the premier inconveniences that prime concern is trying to watch the methods in which it influences OP.

The researchers conducted by (Hasan and Al-Hawari (2003) and Claycomb, Droge and Germain (2002) and Skyrme, 2001) also prove that there is direct relationship between KM and OP. During 2005, Darroch conducted an experiential study to sustenance the part of KM performs within organizations and this study was conducted after analysis of data gathered from CEOs of the companies with fifty or more workers; the study benevolences KM as a synchronizing instrument. This research suggests that an organization having KM capability will utilize resources more proficiently and vice vrsa. Accordingly, it is also Organizations having KM capability are able to achieve intelligently competitive advantage Palacios Marqués, D., and José Garrigós Simón, F. (2006). Researches conducted by Mahmoudsalehi, M. (Tehran, Iran) categorizes the influence of organizational structure (OS) on KM and identifies the prominence of this variable in creation, sharing and utilization of knowledge. The study conducted by Khalil, Safari (2012) suggests that Organizational Structure (OS) has direct relationship with KM. If the features of OS were less integrated, less formal, more complex and more cohesive, the levels of KM would be boosted. Baer and Frese's (2003) think about recommended that atmosphere for start goes about as a positive mediator between process advancement and OP. Damanpour, Walker and Avellaneda's (2009) focus on investigation of the consequences of gathering of advancement sorts and found the beneficial outcome of innovativeness on OP. From this time forward, contemplated that aggregate choice of advancement sorts after some time has a positive association with Organizational Performance. The relationship amongst ingenuity and forthcoming enactment has been examined by Bowen, Rostami and Steel (2010). Now with the passage of time the number of organizations have launched KM initiatives. The practitioners are visualizing following questions in their mindsets:

1. Is it categorically meaningful to capitalize in KM?

2. Will the execution of KM be an achievement story?

3. Will our KM system become efficient?

In the viewpoint of practitioners emphasis should first on the improvement of knowledge performance, e.g. process improvement, innovations, product development, learning and individual growth and consequently look for the influence of knowledge associated activities on OP. According to the prevailing researches, IT has also been apprehended as one of the variable due to which KM also affects. The firms have now started implementing Enterprise resource planning (ERP). The author of this paper focused on (ERP) due to the improved interest on the correlation amongst ERP and OP. Dehning and Richardson (2002) aimed at classifying the correlation amid ERP and OP. According to this study, the execution of (ERP) has a progressive influence on OP; the impact of which is smaller in instantly after implementation and strengthened with the passage of time. Similar study was also conducted by Velcu (2007) who observed the influence of realizing ERP system on $\mathrm{OP}$ and this research was conducted in eight firms in Finland. The role of leadership variable also cannot be ignored and is found to be an extremely important variable in organizational diagnostic models developed by Saeed, B. B., and Wang, W. (2013).The impact of Leadership on OP is possibly the extremely important. Weiner and Mahoney (1981) studied the leadership in one hundred and ninety three industrial firms. As per this research, managerial practices have substantial influence on OP. López-Nicolás, C., and Meroño-Cerdán, Á. L. (2011) has suggested that leadership is a significant and considerable component for the success of an organization. The concept of "Organizational culture (OC)" has also been considered an important variable having impact on KM and OP. This concept is mostly expressed as "knowledge sharing culture"King, W. R. (2007). In a research carried out by Ernest and Young Institute on four hundred and thirty one European and American firms, Cross, R., and Baird, L. (2000)specified that OC is the foremost hindrance in knowledge transfer. In study conducted by (McCann and Buckner,2004), cultural obstacles one of the core variables which hinders the implementation of KM values. Inculcation of an efficient and effective culture emphasizes on knowledge sharing, trust in interfaces and creativeness (Lawson, 2003). KM Scientists exploring the role of leadership on knowledge creation have concentrated on concerns such as distinguishing the role of leadership in KM (Bryant, 2003); scrutinizing the extent to which leadership plays towards creativity inside the organizations (Shin and Zhou, 2003;Chow, and Wu, 2003;Pieterse, Knippenberg, Gumusluoglu and Ilsev, 2009;Schippers, and Stam, 2010;Tse and Mitchell, 2010).

\section{DATA AND METHODOLOGY}

Knowledge Management (KM) is a perception which fist of all used approximately two decades ago, roughly in 1990. Davenport (1994) presented the still broadly cited description: "KM is the procedure of capturing, distributing, and effectively using knowledge." The global of KM is to generate significance and to effect, enhance and upgrade the organizational proficiencies and knowledge resources to meet the goals set by the Knowledge Management Organizations (KMO). Implementing KM has numerous extents including Organizational Culture, Organizational structure, Leadership and 
Infrastructure Technology. Over the last two decades, KM has developed from evolving thought to progressively conjoint task in organizations. This paper shows that KM is absolutely related with OP after having going through the literature surveys as mentioned earlier. The authors found that KM practices have strong impact on numerous transitional practices of OP and that those transitional processes are in turn connected with financial performance. The efficiency towards the achievement of overall goals and set targets for the organization depends on by what means well the improved, critical knowledge is functional in the organization.

Organizational Performance (OP) includes three particular ranges of firm results:

1. $\quad$ Financial performance (benefits, return on assets, rate of gainfulness, etc.);

2. Market performance (bargains, bit of the general business, etc.); and

3. Shareholder return (indicate shareholder return, financial regard included, etc.)

The investigation of an Organization's performance when contrasted with the set objectives and targets/goals. Inside corporate organizations, financial performance, advertise performance and shareholder esteem performance assume an indispensable part in the achievement of any association. Conspicuous change Systems may incorporate a portion of the methodologies for a planned, complete way to deal with expanding OP.

Organizations have a crucial part in our regular daily existences and thusly, productive organizations address a key component for making nations. In this way, various financial experts consider OP like an instrument in picking the cash related, societal and radical advancement. Within corporate organizations, financial performance, market performance and shareholder value performance play a vital role in the success of any organization. Prominent improvement Systems may include some of the approaches for a premeditated, comprehensive approach to increasing OP.

Various leveled hypotheses that took after reinforced the probability of an organization that completes its execution targets considering the objectives compelled by the classified resources Gavrea, C., Ilies, L., and Stegerean, R. (2011). In this setting, improvement got the prospects to be one of the various indicators of performance. The researchers Gavrea, C., llies, L., and Stegerean, R. (2011) give a plan of definitions to speak to the possibility of OP. To report an OP level, it is important to have the capacity to measure the outcomes.

Organizational Structure (OS) is another critical variable which influences KM practices. Solid and sound culture develops and underpins the KM practices and the other way around. To execute KM in an enhanced way, a few organizations put the positions like Chief Knowledge Officer (CKO), Knowledge Engineer (KE), Knowledge Analyst (KA), Knowledge Manager, and Knowledge Steward to administrate KM. OS ought to bolster the strategies, mission, and visualization and ought to rouse groups to share data and produce new learning keeping in mind the end goal to accomplish the craved results. In this setting there must be a solid concentrate on individual and organizational upgrade. Organizational structure is the progression or shape and picks within structure of the associations winning in the relationship, it delineates the divisions or units of the key and branch got a handle on differing activities and exercises required to complete the objectives of the association Haan, S. An., and Kloub, M. A. (2013) It joins the explore of the association and style of oblige and fundamental activity style, so that the strategy for the hierarchical structure and workforce in the association need to affect their capacity to take an interest and imagination Al Awamlah, H. S. (2013), Strategy of shared relations between the parts and segments of the affiliation, this idea demonstrates to the demand of drive with the genuine goal of adequately objectives Haan, S. An., and Kloub, M. A. (2013). We live in a rapidly transformative time, group of organizations and the gathering of knowledge, development, and data modernization dependably represented by progression associated with the past. The response organizations add up to requirement for these natural elements, etc., at the level of organizational change that addresses the goals, approaches and conditions hierarchical, and especially their structures to be able to accomplish a concordance between soundness a change (Alateat,2006). The agents investigated the OS in its idea and estimations, sorts and segments influencing it and considered by Haan, S. A., and Kloub, M. A. (2013) as a person from the association in when he considers researchers to be an after effect of the OP and OS apparatus or a way to exhibit the segments and connections vertical and even, and how to play out the elements of the organization. Haan, S. A., and Kloub, M. A. (2013) specified that a portion of the early expert like March and Simon who portray the Organizational structure that the affiliation structure is a style work blueprint and spread to agents with ultimate objective of conclusion of particular targets (Aqili ,1994). Faulconbridge, J. R., Beaverstock, J. V., Muzio, D., and Taylor, P. J. (2007) specified that the human alone is equipped for building knowledge era and reused notwithstanding the improvement of data innovation and robotization, documentation and capacity of data, ability and speculation and shares them to make and produce knowledge vital procedure of the association. In this manner the way toward planning the organizational structure get to be powerful instrument to encourage KM and advantage from the legitimization of basic leadership by changing over tacit knowledge to explicit knowledge to develop the organizational knowledge base (Althahr,2009). 
Effective Organizational Culture: The Relationship among Culture and KM can affect learning organization in various ways. The explanation for social learning organization is that presupposed particular estimations of an affiliation can achieve incredible and moreover unfavorable conduct and likewise coming about knowledge administration handling. For instance constructive goal and inspiration for trading knowledge, strength of a decent substance is an association and proportional trust between, individual would influence knowledge administration decidedly. The result of champion among the latest studies showed this is not considerable in all alliance. (Ruler and Marks ,2008).

The Effect of Organizational Culture on KM: Culture requires frameworks for current knowledge era and declaration. Tilchin, O., and Essawi, M. (2013) in their studies highlighted the noticeable quality of a compelling organizational Culture for the transmission and origination of knowledge. The discernment behind social KM is that assumed estimations of KMO can be the result in empowering and also contradicted execution which thusly influences KM handling decidedly or unfavorably. Solid aspiration and energy for knowledge trade would bring about influencing the KM decidedly though hesitance for exchanging knowledge are amongst impacts which influence KM unfavorably and in this way will influence the OP in adversative way. Notwithstanding this KM and business procedures are adjusted to each other emphatically to upgrade OP. The sound and solid Quality situated culture bolsters the selection of best practices like Balanced Scorecard, Benchmarking, Reengineering, Continuous Improvement and Strategic Planning towards accomplishing execution perfection in the association.

Leadership and KM: The leadership variable is in like manner routinely found in organizational diagnostic models Gavrea, C., Ilies, L., and Stegerean, R. (2011) The effect of this variable on organizational execution is likely the most clear of the models' segments being the point of different studies. We can demonstrate here the study drove in 1981 by Weiner and Mahoney (1981) who considered the power in 193 storing up affiliations. According to this study, management improves altogether influence two OP portions: profit and share cost.

KM and a sound key leadership assumes an extremely dynamic part in accomplishing magnificence in OP. Without Strategic Leadership, KM is bound to fail. Pioneers practice a noteworthy impact on their associations' KM highlights. Pioneers' execution can decide how much knowledge is looked for, refined, drew in and shared. Organizational qualities, organizational leadership, and Organizational Knowledge progressions assume fundamental parts in overpowering human deterrents identified with knowledge creation, exchange and sharing.

Technology infrastructure needs to have the applicable competencies to support business practices with knowledge dissemination. Infrastructure Technology is a facilitator in conception, apprehending, transfer and integration of knowledge. Information Technology has been discovered in the study with respect to a solitary variable, particularly how much organization have realized an organized Enterprise Resource Planning (ERP) system. We focused on this variable in view of the extended excitement on the relationship between the ERP structure and progressive execution. ERP is a standard programming pack that gives facilitated trade planning and access to information that navigates various progressive units and different business limits (Wu and Wang, 2006).

One study went for perceiving the relationship between the ERP and OP has a place with Velcu, O. (2007). As demonstrated by these creators, the execution of the ERP system emphatically influences OP, the measure of its impact is more diminutive rapidly after utilization, being reinforced after some time. Components of the Knowledge Management Organization (KMO) include an appropriate Organizational structure, Technology Infrastructure, effective Organizational Culture and effective Leadership. All these components when clubbed together may create OP throughout the organization. 
Figure 1: Model of Knowledge Management (KM) and Organizational Performance (OP)

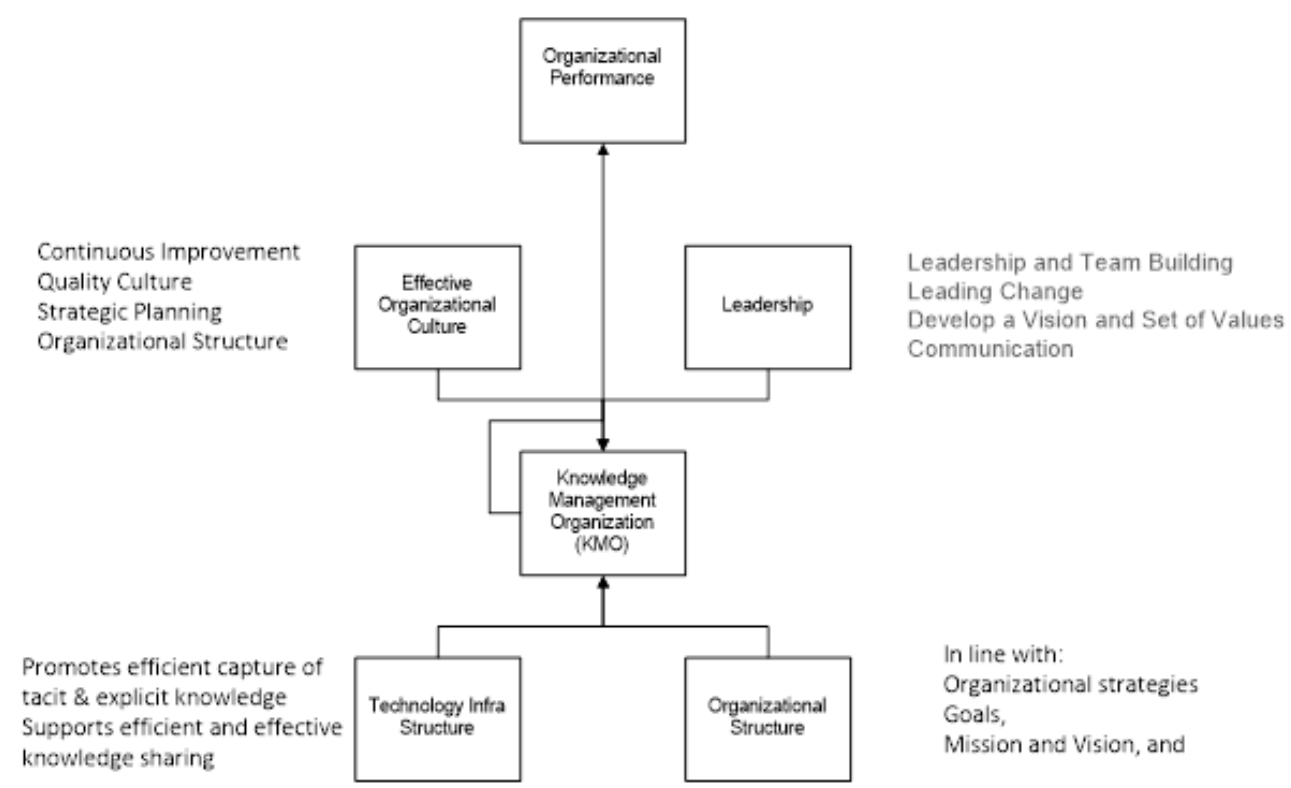

\section{CONCLUSION}

Leadership, Effective Organizational Culture, Technology Infrastructure and Organizational Culture are the critical success factors of a Knowledge Management Organization (KMO) and these can contribute towards achieving OP throughout the Organization. Nonetheless, this study intends to explore the theoretical standing of system-oriented approach by examining the direct relation of KM and OP. Organizational performance has a significant positive relationship with the OP which supports the logic that innovation comes from creativity which is the source of sustainable competitiveness for business organizations (Nonaka et al., 2014). Thus, the present study gives new insights to the researchers, practitioners and strategists. It is predictable that this framework can perform a role in management of the practices of KM implementation in order to explore impact on OP. On the basis of the detailed and comprehensive literature survey on the topic, the author proposes a framework describing the impact of Knowledge Management (KM) practices on Organizational Performance (OP) as follows.

\section{REFERENCES}

Nonaka, I., Kodama, M., Hirose, A., and Kohlbacher, F. (2014). Dynamic fractal organizations for promoting knowledge-based transformation-A new paradigm for organizational theory. European Management Journal, 32(1), 137-146.

Haan, S. A., and Kloub, M. A. (2013). Impact of organizational structure on knowledge management in the Jordanian insurance companies: from the perspective of the supervisory leadership. International Journal of Business and Social Science, 4(11).

Tilchin, O., and Essawi, M. (2013). Knowledge Management through Organizational Culture Change. International Journal of Business Administration, 4(5), 24.

Al Awamlah, H. S. (2013). The Impact of Organizational Justice at Organizational Conflict Level between Its Parties: A Field Study in Jordan Public Administration. International Journal of Business Administration, 4(6), 62.

Saeed, B. B., and Wang, W. (2013). Organisational diagnoses: a survey of the literature and proposition of a new diagnostic model. International Journal of Information Systems and Change Management, 6(3), 222-238.

Tompson, H. B., and Tompson, G. H. J. (2013). The focus of leadership development in MNCs. BOOK REVIEW: THE MYTH OF LEADERSHIP (2004) BY JS NIELSEN, 8(1), 6.

Tubigi, M. A., and Alshawi, S. N. (2012). The impact of knowledge management processes on organisational performance. 
Von Krogh, G., Nonaka, I., and Rechsteiner, L. (2012). Leadership in organizational knowledge creation: a review and framework. Journal of Management Studies, 49(1), 240-277.

Tubigi, M. A., and Alshawi, S. N. (2012). The impact of knowledge management processes on organisational performance.

Mahmoudsalehi, M., Moradkhannejad, R., and Safari, K. (2012). How knowledge management is affected by organizational structure. The Learning Organization, 19(6), 518-528.

Damanpour, Fariborz, and Deepa Aravind. "Managerial innovation: Conceptions, processes, and antecedents." Management and Organization Review 8, no. 2 (2012): 423-454.

Zaied, A. N. H. (2012). An integrated knowledge management capabilities framework for assessing organizational performance. International Journal of Information Technology and Computer Science (IJITCS), 4(2), 1.

Gavrea, C., Ilies, L., and Stegerean, R. (2011). Determinants of organizational performance: The case of Romania. Management and Marketing, 6(2), 285

López-Nicolás, C., and Meroño-Cerdán, Á. L. (2011). Strategic knowledge management, innovation and performance. International journal of information management, 31(6), 502-509.

Mitchell, R., and Boyle, B. (2010). Knowledge creation measurement methods. Journal of Knowledge Management, 14(1), 67-82.

Bratianu, C., and Orzea, I. (2010, March). Tacit knowledge sharing in organizational knowledge dynamics. In Proceedings of the 2nd European Conference on Intellectual Capital (pp. 107-1114).

Bowen, Frances E., Mahdi Rostami, and Piers Steel. "Timing is everything: A meta-analysis of the relationships between organizational performance and innovation." Journal of Business Research 63, no. 11 (2010): 1179-1185.

Shoham, S., and Perry, M. (2009). Knowledge management as a mechanism for technological and organizational change management in Israeli universities. Higher education, 57(2), 227-246.

Zack, M., McKeen, J., and Singh, S. (2009). Knowledge management and organizational performance: an exploratory analysis. Journal of knowledge management, 13(6), 392-409.

Althahr, Naim, (2009),"Knowledge Management", Irbid, modern world of books for publication and distribution, Amman, Jadara World Book Publishing and Distribution.

Marks, G., Hooghe, L., and Schakel, A. H. (2008). Patterns of regional authority. Regional and Federal Studies, 18(2-3), 167-181.

Seidler-de Alwis, R., and Hartmann, E. (2008). The use of tacit knowledge within innovative companies: knowledge management in innovative enterprises. Journal of knowledge Management, 12(1), 133-147.

Jasimuddin, S. M. (2008). A holistic view of knowledge management strategy. Journal of Knowledge Management, 12(2), 57-66.

Faulconbridge, J. R., Beaverstock, J. V., Muzio, D., and Taylor, P. J. (2007). Global law firms: Globalization and organizational spaces of crossborder legal work. Nw. J. Int'l L. and Bus., 28, 455.

Zaim, H., Tatoglu, E., and Zaim, S. (2007). Performance of knowledge management practices: a causal analysis. Journal of knowledge management, 11(6), 54-67.

Frese, M., Garst, H., and Fay, D. (2007). Making things happen: reciprocal relationships between work characteristics and personal initiative in a four-wave longitudinal structural equation model. Journal of Applied Psychology, 92(4), 1084.

Velcu, O. (2007). Exploring the effects of ERP systems on organizational performance: Evidence from Finnish companies. Industrial Management and Data Systems, 107(9), 1316-1334.

King, W. R. (2007). A research agenda for the relationships between culture and knowledge management. Knowledge and process management, 14(3), 226-236.

Palacios Marqués, D., and José Garrigós Simón, F. (2006). The effect of knowledge management practices on firm performance. Journal of Knowledge Management, 10(3), 143-156.

Tsui, A. S., Zhang, Z. X., Wang, H., Xin, K. R., and Wu, J. B. (2006). Unpacking the relationship between CEO leadership behavior and organizational culture. The Leadership Quarterly, 17(2), 113-137.

Smith, K. G., Collins, C. J., and Clark, K. D. (2005). Existing knowledge, knowledge creation capability, and the rate of new product introduction in high-technology firms. Academy of management Journal, 48(2), 346-357.

Darroch, J. (2005). Knowledge management, innovation and firm performance. Journal of knowledge management, 9(3), $101-115$.

Mortensen, P. S., and Bloch, C. W. (2005). Oslo Manual-Guidelines for collecting and interpreting innovation data. Organisation for Economic Cooporation and Development, OECD. 
McCann, J. (2004). Organizational effectiveness: Changing concepts for changing environments. People and Strategy, $27(1), 42$.

Sher, P. J., and Lee, V. C. (2004). Information technology as a facilitator for enhancing dynamic capabilities through knowledge management. Information and management, 41(8), 933-945.

Lawson-Borders, G. (2003). Integrating new media and old media: Seven observations of convergence as a strategy for best practices in media organizations. International Journal on Media Management, 5(2), 91-99.

Choi, B., and Lee, H. (2003). An empirical investigation of KM styles and their effect on corporate performance. Information and Management, 40(5), 403-417.

Bryant, S. E. (2003). The role of transformational and transactional leadership in creating, sharing and exploiting organizational knowledge. Journal of Leadership and Organizational Studies, 9(4), 32-44.

Darroch, J., and McNaughton, R. (2003). Beyond market orientation: Knowledge management and the innovativeness of New Zealand firms. European journal of Marketing, 37(3/4), 572-593.

Lee, H., and Choi, B. (2003). Knowledge management enablers, processes, and organizational performance: An integrative view and empirical examination. Journal of management information systems, 20(1), 179-228.

Dehning, B., and Richardson, V. J. (2002). Returns on investments in information technology: A research synthesis. Journal of Information Systems, 16(1), 7-30.

Schulz, M., and Jobe, L. A. (2001). Codification and tacitness as knowledge management strategies: an empirical exploration. The Journal of High Technology Management Research, 12(1), 139-165.

Bollinger, A. S., and Smith, R. D. (2001). Managing organizational knowledge as a strategic asset. Journal of knowledge management, 5(1), 8-18.

Eisenhardt, K. M., and Martin, J. A. (2000). Dynamic capabilities: what are they?. Strategic management journal, 21(10-11), 1105-1121.

Cross, R., and Baird, L. (2000). Technology is not enough: Improving performance by building organizational memory. MIT Sloan Management Review, 41(3), 69.

Gupta, B., Iyer, L. S., and Aronson, J. E. (2000). Knowledge management: practices and challenges. Industrial Management and Data Systems, 100(1), 17-21

Cook, S.D.N. and Brown, J. S. Bridging Epistemologies: The Generative Dance between Organizational Knowledge and Organizational Knowing. Organization Science, (10:4) 1999, pp. 381-400

Nonaka, I., Umemoto, K., and Senoo, D. "From information processing to knowledge creation: A paradigm shift in business management," Technology in Society (18:2) 1996, pp 203-218.

Nonaka, I., and Takeuchi, H. (1995). The knowledge-creating company: How Japanese companies create the dynamics of innovation. Oxford university press.

Ring, P. S., and Van de Ven, A. H. (1994). Developmental processes of cooperative inter organizational relationships. Academy of management review, 19(1), 90-118.

Nonaka, I. "A Dynamic Theory of Organizational Knowledge Creation," Organization Science (5:1), Feb 1994, pp 14-37.

Nonaka, I., Byosiere, P., Borucki, C. C., and Konno, N. (1994). Organizational knowledge creation theory: a first comprehensive test. International Business Review, 3(4), 337-351.

Drucker, P. (1992). The society of organizations. Harvard business review, 95-104.

Cameron, K. (1983). Organizational effectiveness. John Wiley and Sons, Ltd.

Weiner, N., and Mahoney, T. A. (1981). A model of corporate performance as a function of environmental, organizational, and leadership influences. Academy of management Journal, 24(3), 453-470.

Seashore, S. E., and Yuchtman, E. (1967). Factorial analysis of organizational performance. Administrative Science Quarterly, 377-395. 